\title{
A Viability Assay for Tetrahymena pyriformis
}

\author{
By D. P. HEAF AND D. LEE \\ Clinical Research Centre, Watford Road, Harrow HAI 3 UJ
}

(Accepted for publication 2 August I971)

In experiments where cells are subjected to stresses that damage only a fraction of the population, it is essential to have an estimate of the number of cells which survive the procedure.

We have used the ciliated protozoon Tetrahymena pyriformis as a model cell for such studies and there are a number of reports in the literature of techniques which have been used to estimate the concentration of cells in cultures of this organism. Ricketts (1970) used a counting chamber, Lee (I969) and Erwin (I970) used turbidimetry, and electronic counting has been used by many authors, for example, by Pearlman \& Westergaard (I969), by Leick, Engberg \& Emmersen (1970) and by Curds \& Cockburn (1968). However, all of these methods count both living and dead cells.

Two reports have appeared in which the number of ciliated protozoa surviving freezing and thawing was assessed by observing motility (Hwang, Davis \& Alexander, 1964; Wang \& Marquardt, 1966) but this is a tedious procedure and, as motility during the first hour after thawing may not give an accurate assessment of viability (Simon, I97I), it seemed desirable to develop a viability assay based on reproductive capacity.

The standard viability assay used for bacteria (Cruickshank, 1969) cannot be used with Tetrahymena pyriformis as this protozoon will not grow on agar plates and a different method of plating was therefore developed. This communication describes a viability assay in which plating was done using a liquid medium.

\section{METHODS}

Materials. Tryptone and yeast extract were obtained from Oxoid Ltd, London, S.E. I, haemagglutination trays from Manuplastics Ltd, London, S.W. 20 and lightweight polythene bags from Transatlantic Plastics Ltd, London, S.W. 6.

Cultivation of cells. Tetrahymena pyriformis, strain s, was grown axenically in the dark in I \% tryptone $/ 0.05 \%$ yeast extract in the manner described previously (Lee, I969) and subcultures $(0.5 \mathrm{ml}$.) were made into $100 \mathrm{ml}$. of fresh medium every 2 to 3 days. All media used in the assay contained benzylpenicillin (50 units $/ \mathrm{ml}$.), streptomycin sulphate $(50 \gamma / \mathrm{ml}$.) and griseofulvin $(20 \gamma / \mathrm{ml}$.) as a precaution against contamination obtained in the course of the experiments.

Assay method. It was not desirable to use turbidimetry to estimate the number of protozoa in a culture due to the large errors involved when the concentration of organisms was low and although electronic counting has come into widespread use, it has proved unsatisfactory in our hands because of coincidence problems when the orifice used was large and clogging when the orifice was small. For these reasons, the organisms in a sample suspension of a culture were immobilized by addition of formaldehyde until its final concentration was $4 \%(\mathrm{w} / \mathrm{v})$ and were then counted by means of a counting chamber. A sufficient 
number of organisms was counted such that the standard deviation of the total was less than $5 \%$.

Dilutions of the original culture were made into flasks containing $400 \mathrm{ml}$. of media (and a plastic-coated magnetized follower) so that the concentration of organisms in these flasks was between 50 and 400 organisms $/ 1$. Samples $(0.5 \mathrm{ml}$.) were then removed from the stirred flasks with a Cornwall syringe continuous pipetting outfit (Becton Dickinson Ltd, Wembley, Middlesex) and placed in the cups of 80-hole perspex haemagglutination trays. The trays had previously been sterilized by exposure for $\mathrm{I}$ h. to the light from an ultraviolet bactericidal lamp (Model I2, Hanovia Lamps Ltd, Slough, Buckinghamshire) which had a power output of 3 watts and $80 \%$ of its emission at $254 \mathrm{~nm}$. During sterilization the plates were wrapped in lightweight polythene bags and, after plating, the trays were again wrapped in the same polythene bags. Assuming perfect mixing and sampling, these procedures result in the distribution of 2 to 16 organisms into 80 separate subcultures.

After incubation for 6 days at the optimum growth temperature of $28^{\circ}$, the cups in each plate were examined for signs of growth. Viable organisms gave rise to populations in which the organisms looked like grains of sand and could therefore be counted with the naked eye over a Coldlight Illuminator (Kodak Ltd, London, W.C.2). The number of cups containing populations was recorded and assumed to equal the number of viable cells plated. Plating efficiency was defined as the ratio of the number of viable organisms to the number of organisms plated and was expressed as a percentage.

Plates which had been sterilized by exposure to ethylene oxide vapour failed to support any growth whatsoever. This was presumably due to absorbtion of ethylene oxide by the perspex haemagglutination trays in the same way that it is known to be absorbed by other materials (Gunther, 1969; Stanley, Bertranou, Forest \& Langevin, 197I).

\section{RESULTS}

The relationship between the number of organisms plated and the number of cups which contained populations after incubation is theoretically linear with low concentrations of cells and Fig. I shows an example where the plating efficiency was close to $100 \%$. Obviously, the procedure gives rise to the possibility of having more than one organism in each cup at

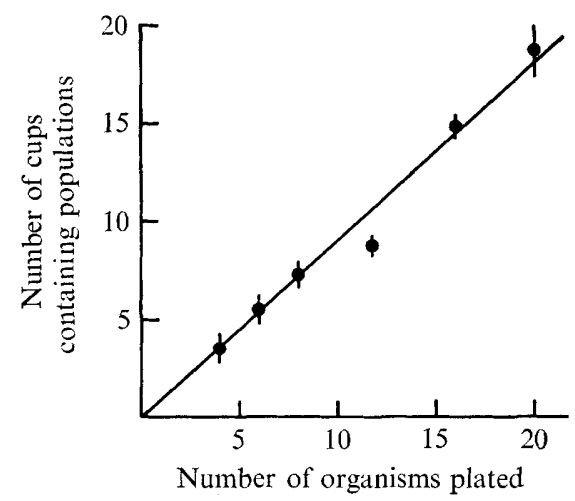

Fig. I. Mean number of cups containing populations 6 days after plating samples of media containing different concentrations of cells. The points represent the mean observed using six plates at each concentration and the bars show the standard error. The line shown is the best fit line through the mean values and the plating efficiency was $93 \%$. 
the time of plating, and this situation would give rise to non-linear responses as the concentration of organisms became greater. In fact there is less than a $10 \%$ probability of having more than one organism per cup when the number of populations is below twenty and, in practice, noticeable deviations from linearity were not observed until there were about forty populations per plate.

The plating efficiencies observed were sometimes noticeably less than $100 \%$ and were sometimes as low as $50 \%$. This appeared to be dependent on the batch of yeast extract used, and also on the age of the culture, the efficiency decreasing as the culture became older. However, this variability should not prevent use of the assay in a study of the number of cells surviving stresses such as freezing and thawing as the organisms will presumably have the same plating efficiency before and after such treatment.

Clearly this plating procedure could be used for the assay of other micro-organisms which can be obtained in pure culture but which are unable to form colonies on agar.

We are indebted to Miss Iris Robertson of the Statistical Services Section, National Institute for Medical Research, for valuable statistical advice and to Miss Jacqueline Osborne for excellent technical assistance.

\section{REFERENCES}

Cruickshank, R. (1969). In Medical Microbiology, i th edn, p. 980. Edinburgh: Livingstone.

Curds, C. R. \& CockBurn, A. (1968). Studies on the growth and feeding of Tetrahymena pyriformis in axenic and monoxenic culture. Journal of General Microbiology 54, 343-358.

ERwIN, J. A. (1970). The reversal of temperature-induced cell-surface deformation in Tetrahymena by polyunsaturated fatty acids. Biochimica et biophysica acta 202, 2 I-34.

GuNTHER, D. A. (1969). Absorption and desorption of ethylene oxide. American Journal of Hospital Pharmacy 26, 45-49.

Hwang, S., Davis, E. E. \& Alexander, M. T. (1964). Freezing and viability of Tetrahymena pyriformis in dimethylsulfoxide. Science, New York 144, 64-65.

LEE, D. (1969). Photolysis in a culture medium for Tetrahymena pyriformis. Journal of Cellular Physiology 74, $295-298$.

Leick, V., ENGBerg, J. \& Emmersen, J. (1970). Nascent subribosomal particles in Tetrahymena pyriformis. European Journal of Biochemistry 13, 238-246.

Pearlman, R. \& WestergaArd, O. (I969). DNA polymerase activity from exponentially multiplying and division synchronized Tetrahymena. Comptes rendus des travaux du Laboratoire Carlsberg 37, 77-86.

RICKETTS, T. R. (1970). Effect of endocytosis upon acid phosphatase activity of Tetrahymena pyriformis. Protoplasma 71, I27-137.

Simon, E. M. (1971). Paramecium aurelia: Recovery from - 196 ${ }^{\circ}$ C. Cryobiology 8, 361-365.

Stanley, P., Bertranou, E., Forest, F. \& Langevin, L. (1971). Toxicity of ethylene oxide sterilization of polyvinylchloride in open heart surgery. The Journal of Thoracic and Cardiovascular Surgery 6r, 309-314.

WANG, G. \& MARQuardt, W. C. (1966). Survival of Tetrahymena pyriformis and Paramecium aurelia following freezing. Journal of Protozoology 13, 123-128. 